\title{
Physiological Response to Whole-Body Vibration in Athletes and Sedentary Subjects
}

\author{
B. GOJANOVIC ${ }^{1,2}$, F. FEIHL ${ }^{1}$, G. GREMION ${ }^{2}$, B. WAEBER ${ }^{1}$ \\ ${ }^{1}$ Department of Medicine, Lausanne University Hospital and University, Lausanne, Switzerland, \\ ${ }^{2}$ Swiss Olympic Sports Medicine Center, Department of Human Locomotion, Lausanne University \\ Hospital and University, Lausanne, Switzerland
}

Received July 30, 2013

Accepted March 13, 2014

On-line August 26, 2014

\section{Summary}

Whole-body vibration (WBV) is a new exercise method, with good acceptance among sedentary subjects. The metabolic response to WBV has not been well documented. Three groups of male subjects, inactive (SED), endurance (END) and strength trained (SPRINT) underwent a session of side-alternating WBV composed of three 3-min exercises (isometric half-squat, dynamic squat, dynamic squat with added load), and repeated at three frequencies $(20,26$ and $32 \mathrm{~Hz}) . \mathrm{VO}_{2}$, heart rate and Borg scale were monitored. Twenty-seven healthy young subjects (10 SED, 8 SPRINT and 9 END) were included. When expressed in $\%$ of their maximal value recorded in a treadmill test, both the peak oxygen consumption $\left(\mathrm{VO}_{2}\right)$ and heart rate $(\mathrm{HR})$ attained during WBV were greatest in the SED, compared to the other two groups $\left(\mathrm{VO}_{2}: 59.3 \%\right.$ in SED vs $50.8 \%$ in SPRINT and $48.0 \%$ in END, $\mathrm{p}<0.01$; HR $82.7 \%$ in SED vs $80.4 \%$ in SPRINT and $72.4 \%$ in END, $\mathrm{p}<0.05)$. In conclusions, the heart rate and metabolic response to WBV differs according to fitness level and type, exercise type and vibration frequency. In SED, WBV can elicit sufficient cardiovascular response to benefit overall fitness and thus be a potentially useful modality for the reduction of cardiovascular risk.

\section{Key words}

Exercise • Oxygen consumption • Heart rate • Sedentary lifestyle - Vibration

\section{Corresponding author}

B. Gojanovic, DAL - Sports medicine, Lausanne University Hospital CHUV, CH-1011 Lausanne, Switzerland. E-mail: boris.gojanovic@chuv.ch

\section{Introduction}

Whole-body vibration (WBV) is a fairly recent training modality, commercially available since the start of the millennium. It has been developed in the 1970s in the former Soviet Union, with the purpose of training cosmonauts in order to prevent loss of bone mineral and muscle mass during space flights, and the first reports on athletic training came after 1985 (Nazarov and Spivak 1985). It is nowadays widely used for personal training purposes, with numerous claims from manufacturers, encompassing enhanced muscular strength, bone mass, proprioception, balance, flexibility, along with beneficial metabolic effects, such as augmentation in lipolysis, glucose tolerance, growth hormone and testosterone secretion. Some but not all of these claims are supported by data (Verschueren et al. 2004, Bautmans et al. 2005, Bruyere et al. 2005, Gusi et al. 2006, Rehn et al. 2007, Cardinale et al. 2010, Slatkovska et al. 2010). The subjects in the various trials vary greatly in age, metabolic profile, physical activity levels or types of sports they are actively involved in, and these issues have been recently addressed elsewhere (Cochrane 2011). The review papers trying to sort out the effects observed with this training method all single out the need for standardization of the exercise protocols, especially regarding the type of vibratory stimulus used (vertical and/or lateral plate displacement, or side-alternating oscillation around a fixed center axis), duration of exercise bouts, number of repetitions, frequency and amplitude of platform movement (Lorenzen et al. 2009). All of these parameters vary considerably between the 
different trials, resulting in manufacturers claiming effects observed in trials conducted with different machines and specifications of platform movement. Nevertheless, since the vibration platforms are widely available for athletes and non-athletic subjects looking for ways to improve their general health, it seems useful to have comparative data for the same exercises in differently trained subjects.

The importance of physical activity in maintenance or improvement of general health is widely accepted, and is based on the observation that the higher the fitness level, the better the outcome with regards to health (Sesso et al. 2000, Myers et al. 2002, Warburton et al. 2006). The potential benefit of WBV towards promotion of overall fitness has not been ascertained, and findings regarding the impact on aerobic fitness are equivocal. Bogaerts et al. (2009) have observed an $18.6 \%$ improvement in $\mathrm{VO}_{2} \mathrm{max}$ in elderly inactive women, after 12 months of WBV training, while Vissers et al. (2010) have found no such improvement after 6 months of WBV in overweight and obese middle-aged subjects. During acute WBV exposure, a few studies have observed no or little effect on heart rate or oxygen uptake during WBV exercices (Rittweger et al. 2001, Hazell et al. 2008). There definitely is a lack of understanding and agreement regarding the cardiovascular response elicited by WBV training in general.

In the present study, we aimed to investigate the physiology of vibration training, particularly the cardiac and metabolic response to various exercises at various frequencies. We hypothesized that baseline fitness levels will influence the response to the vibratory stimulus, which is why we chose sedentary subjects and two athletic populations. We aimed at identifying the maximal metabolic and heart rate load attainable with the most commonly investigated vibration exercises.

\section{Materials and Methods}

This study was approved by the Institutional Review Board of the University of Lausanne and carried out in accordance with the Declaration of Helsinki. Written informed consent was obtained from each participant.

\section{Subjects}

Twenty-seven male volunteers aged 20 to 40 years old were recruited in local sports organizations and within the Lausanne University community. We used a convenience sample of 10 inactive subjects (SED), 8 strength-velocity trained athletes (SPRINT) and 9 endurance trained athletes (END). The SED group comprised subjects categorized as inactive according to the IPAQ short form questionnaire (Gauthier et al. 2009) minimal physical activity requirements (less than 20 to $60 \mathrm{~min}$ of vigorous physical activity three times a week, or less than $30 \mathrm{~min}$ of moderate physical activity five times a week). Some of them had been active in sports in the past, but not in the last 12 months. The SPRINT group comprised athletes currently active in competitive sports, mostly short distance track sprinters, American football receivers and one decathlete. The END group comprised triathletes and one long-distance runner. All subjects were naïve to vibration training and had been training in their sport for the last two years, a minimum of $5 \mathrm{~h}$ per week, and without a break lasting more than one week in the past three months. Exclusion criteria included smoking, epilepsy, any fracture in the preceding 6 months, any implanted prosthetics, thrombosis in the preceding 3 months, history of diabetes, cardiovascular disease, or lipid disorders. Subjects' characteristics are listed in Table 1.

\section{Data collection}

After a detailed medical history and physical examination, subjects weight, height, blood pressure and body composition parameters were determined by electrical bioimpedance (Body Impedance Analyzer, Nutrigard-M, Frankfurt, Germany). All tests were conducted in a climate controlled (temperature and relative humidity) laboratory.

\section{$\mathrm{VO}_{2}$ max recordings}

Subjects' $\mathrm{VO}_{2} \max$ was directly assessed with the CPX/MAX cardiopulmonary diagnostic system (MedGraphics ${ }^{\circledR}$, St Paul, Minnesota) during a graded exercise treadmill test (initial speed $7 \mathrm{~km} \cdot \mathrm{h}^{-1}$ in SED, $8 \mathrm{~km} \cdot \mathrm{h}^{-1}$ in SPRINT and $10 \mathrm{~km} \cdot \mathrm{h}^{-1}$ in END, $0.5 \mathrm{~km} / \mathrm{h}$ increments per minute). The exercise test was considered maximal when any of the following was fulfilled: plateau in oxygen uptake with increasing work rate, respiratory exchange ratio greater than 1.10 , attainment of expected maximal heart rate $\leq 5 \mathrm{bpm}$, or appearance of symptoms (exhaustion, severe shortness of breath, abnormal stride pattern). The values reported are time-averaged over the last $30 \mathrm{~s}$ of each exercise. Maximal heart rate was recorded and used for further calculations of percentage of maximum (\%HRmax). 


\section{Isokinetic strength testing}

Maximal strength evaluation was carried out on an isokinetic knee extension/flexion machine (Biodex Medical Systems ${ }^{\circledR}$, Shirley, New York). The testing protocol is standardized according to the Swiss Olympic guidelines for athletic evaluation (Tschopp 2003), and consists of 5 repetitions of flexion/extension sequences at an angular velocity of 60 and 180 degrees/s, and 30 repetitions at 300 degrees/s.

Table 1. General characteristics of the three study groups.

\begin{tabular}{|c|c|c|c|c|c|c|}
\hline & SED & SPRINT & END & & p values & \\
\hline Number of subjects & 10 & 8 & 9 & SPRINT vs SED & $E N D$ vs $S E D$ & END vs SPRINT \\
\hline Age (years) & $24.5 \pm 3.3$ & $25 \pm 2.5$ & $29.8 \pm 7.4$ & $n s$ & $n s$ & $n s$ \\
\hline Weight (kg) & $73.9 \pm 7.5$ & $77.4 \pm 12.9$ & $71.9 \pm 4.9$ & $n s$ & $n s$ & $n s$ \\
\hline Height (m) & $1.8 \pm 0.08$ & $1.78 \pm 0.04$ & $1.81 \pm 0.05$ & $n s$ & $n s$ & $n s$ \\
\hline$B M I\left(k g \cdot m^{-2}\right)$ & $22.8 \pm 2.1$ & $24.3 \pm 3.4$ & $21.9 \pm 1.2$ & $n s$ & $n s$ & $n s$ \\
\hline$\%$ body fat & $20.3 \pm 4.3$ & $17.0 \pm 4.8$ & $15.0 \pm 2.2$ & $n s$ & 0.007 & $n s$ \\
\hline$\%$ fat-free mass & $46.2 \pm 5.6$ & $56.7 \pm 9.3$ & $52.1 \pm 6.6$ & 0.007 & $n s$ & 0.007 \\
\hline $\begin{array}{l}\text { Resting heart rate } \\
\text { (bpm) }\end{array}$ & $67.8 \pm 10.6$ & $71.9 \pm 12.8$ & $60.2 \pm 7.9$ & $n s$ & $n s$ & $n s$ \\
\hline \multicolumn{7}{|l|}{$\begin{array}{l}\text { Blood pressure } \\
(\mathrm{mm} \mathrm{Hg})\end{array}$} \\
\hline Systolic & $122.7 \pm 8.2$ & $127 \pm 7.6$ & $126 \pm 7$ & $n s$ & $n s$ & $n s$ \\
\hline Diastolic & $67.6 \pm 5.3$ & $67.8 \pm 6.1$ & $68 \pm 6.9$ & $n s$ & $n s$ & $n s$ \\
\hline $\begin{array}{l}\mathrm{VO}_{2} \max \\
\left(\mathrm{ml} \cdot \mathrm{kg}^{-1} \mathrm{~min}^{-1}\right)\end{array}$ & $47.9 \pm 4$ & $52.9 \pm 6$ & $63.9 \pm 6.5$ & $n s$ & $<0.001$ & $<0.001$ \\
\hline \multicolumn{7}{|l|}{$\begin{array}{l}\text { Peak leg extensor } \\
\text { torque }\left(\mathrm{Nm} \cdot \mathrm{kg}^{-1}\right)\end{array}$} \\
\hline Right & $191.2 \pm 44$ & $252 \pm 41.3$ & $198 \pm 39.4$ & 0.005 & $n s$ & 0.014 \\
\hline Left & $190.8 \pm 39.4$ & $223 \pm 36.9$ & $191 \pm 35.6$ & $n s$ & $n s$ & $n s$ \\
\hline
\end{tabular}

SED, sedentary; SPRINT, strength-velocity trained; END, endurance-trained; BMI, body mass index; $\mathrm{VO}_{2}$ max, maximal oxygen uptake. Peak leg extensor torque reported at an angular velocity of $60^{\circ}$ per second. Difference between right and left leg peak extensor torque non significant in all three groups. Data are mean and \pm SD.

\section{Vibration exercise}

Our oscillatory vibration platform consists of a plate oscillating around a middle axis, with feet placed on either side, resulting in alternating up and down

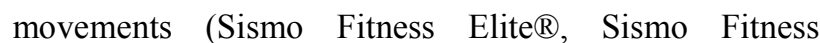
International, 94230 Cachan, France). Vibration frequency range is from 1 to $32 \mathrm{~Hz}$, with peak-to-peak amplitude of $10.4 \mathrm{~mm}$ (middle toe of each foot placed at $22.5 \mathrm{~cm}$ from the center of the platform). Our subjects underwent a short eleven-minute familiarization session on the platform on a separate day, in which they executed three-minute isometric and dynamic squatting without and with added load, with 1 min rest in between. After a five-minute light warm-up on a stationary bicycle (50 Watts), subjects were equipped with gas analyzer and the protocol exercise was started at a frequency of $20 \mathrm{~Hz}$ (peak acceleration $=8.37 \mathrm{~g}$ ), because lower frequencies may be uncomfortable and deleterious due to tissue resonance (Rittweger 2009). Participants were standing on the platform in unpadded socks, with feet placed at a fixed distance of the middle axis to assure constant amplitude. They did three different exercises lasting three minutes each, with one minute rest in between. The first exercise was a semi-squat isometric stance (60 degrees of knee flexion). The second exercise consisted of slow dynamic ( $3 \mathrm{~s}$ down, $3 \mathrm{~s}$ up, to the beat of a $1 \mathrm{~Hz}$ metronome) squats to 90 degrees of knee flexion, i.e. thirty repetitions overall. The third exercise was the same with added load equal to $30 \%$ of body weight in a tightly fitting backpack. After ten minutes of rest, 
this eleven-minute sequence was repeated at $26 \mathrm{~Hz}$ (peak acceleration $=14.15 \mathrm{~g}$ ) and then again at $32 \mathrm{~Hz}$ (peak acceleration $=21.43 \mathrm{~g}$ ). Subjects repeated the same sequence a week apart (hereafter named V1 and V2), to help account for any habituation effect. The exercises and the frequencies have not been randomized, but rather we chose to start with the presumed easier exercises and frequencies to minimize any carry-over fatigue in subsequent exercises.

Heart rate (Polar Electro ${ }^{\circledR}$, Finland) and gas exchange were continuously monitored throughout the experiment, except during the 10 -min resting periods. The $\mathrm{VO}_{2}$ values reported are averaged over the last $30 \mathrm{~s}$ of each exercise, in order to average out breath-to-breath variation and capture the end of the third minute of exercise, where steady-state is habitually attained (Robergs et al. 2010). Subjects could hold the handles in front of them, but only to balance themselves.

\section{Statistical analysis}

Regarding demographic and baseline characteristics, statistical differences between the three groups were evaluated with one-way analysis of variance. The impact of experimental conditions on oxygen uptake (expressed as \% of $\mathrm{VO}_{2} \mathrm{max}$ ), heart rate (expressed as $\%$ of maximal heart rate), and Borg dyspnea score were assessed with analysis of variance for repeated measures. Before analysis, oxygen uptake and heart rate were log transformed because of heteroscedascity. Fixed nominal factors in the model were group membership (3 levels), exercise type (3 levels), and session (2 levels). Vibration frequency was included as a continuous covariate. Subjects nested within group were considered as random effects. Models containing either all 2- and 3-way interactions between the fixed nominal factors or only simple effects were first compared, in terms of goodness of fit. On this basis, and for all three variables, it was decided that the simpler model without interactions was appropriate. The normality asumption was checked from the linear shape of normal quantile plots of residuals. When the omnibus $F$ test for a particular effect was significant, Fisher's least significant differences were used to carry out pairwise comparisons in the case of effects with 3 levels. The alpha level of all tests was set at 0.05. Data are summarized as the mean and SD.

\section{Results}

The subjects' baseline characteristics differed as expected per protocol, reflecting the level of activity of each group. In particular, END had the highest, SPRINT the intermediate and SED the lowest $\mathrm{VO}_{2} \max (\mathrm{p}<0.001$ between groups). BMI, total fat mass, and resting heart rate were also lower in END, although only percent body fat was significantly lower $(p<0.01)$. Percentage of fatfree mass was the highest in SPRINT, intermediate in END and lowest in SED (56.7\% \%9.3 vs. $52.1 \pm 6.6$ vs. $46.2 \pm 5.6, \quad \mathrm{p}<0.001$ between groups), and peak leg extensors torque was similarly distributed (Table 1).

\section{Heart rate response}

In all participants, the maximal measured heart rate response was elicited by the loaded squats at $32 \mathrm{~Hz}$ vibration frequency. In SED, it amounted to $82.7 \% \pm 8.1$ (\% of HRmax) at V1, and $81.7 \% \pm 10.5$ at V2. SPRINT showed a slightly lower response, $80.4 \% \pm 8.5$ and $77.3 \% \pm 10.5$, and END an even lower one, $72.4 \% \pm 7.3$ and $71.6 \% \pm 6.5$. See Figure 1 for all heart rate responses.

\section{Effect of exercise type and vibration frequency}

Heart rate response increased with vibration frequency $(\mathrm{p}<0.01)$ and was different between exercise types (highest for loaded squats and lowest for isometric squats, $\mathrm{p}<0.001)$.

\section{Effect of familiarization}

All subjects were able to manage V2 better, with a lower HR for each exercise $(p<0.01)$. Some subjects were unable to finish the last loaded exercise due to exhaustion in V1, mostly in SED (5 SED, 1 SPRINT, 1 END), while only 3 SED could not finish the last stage in $\mathrm{V} 2$.

\section{Effect of athletic background}

The heart rate response was lower in END than in either SED $(p<0.001)$ or SPRINT $(p<0.05)$, and did not differ between the latter two groups. The addition of age, weight, and BMI as covariates in the repeated measures ANOVA had no impact on the results of statistical analysis.

\section{Oxygen consumption}

Regarding the peak $\mathrm{VO}_{2}$, the effects of the various investigated factors was the same as for HR, reaching $58.8 \% \pm 10.3$ of $\mathrm{VO}_{2} \max (\mathrm{V} 1)$ and $59.3 \% \pm 11.8$ (V2) in SED, $50.8 \% \pm 9.2$ and $46.8 \% \pm 6.9$ in SPRINT, and $48.0 \% \pm 11.3$ and $43.8 \% \pm 11.4$ in END. See Figure 2 for all oxygen uptake responses. 
곤
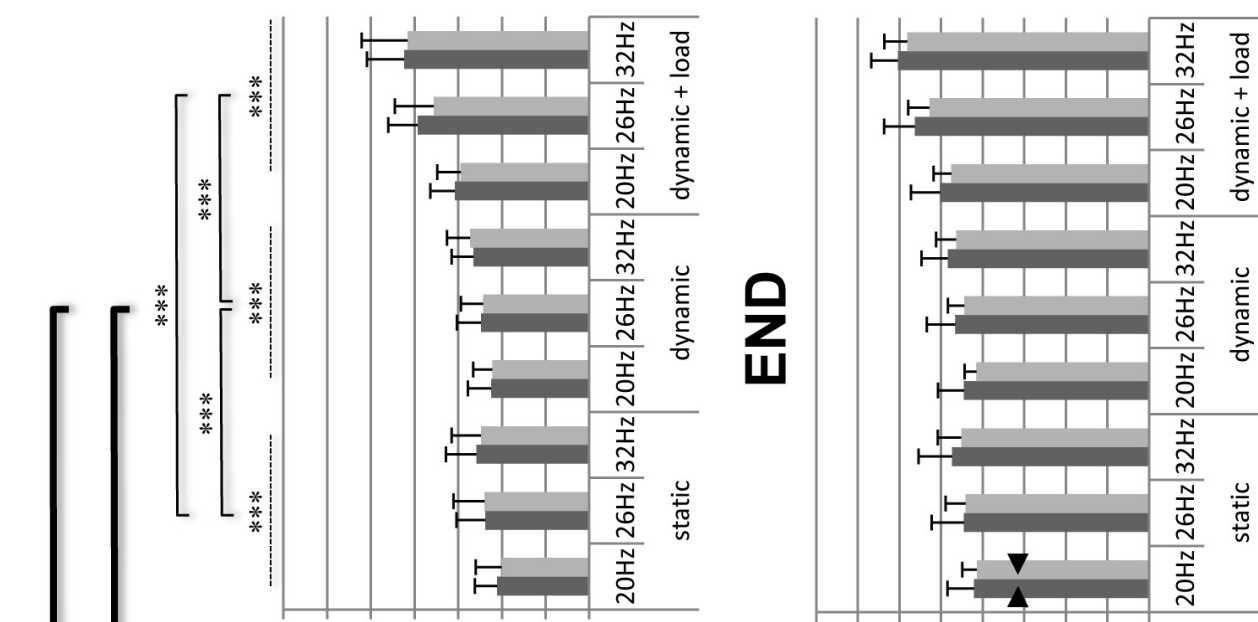

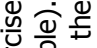

这.

×高

든 号 㔄

言亭跑

苾范品

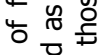

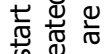

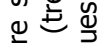

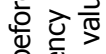

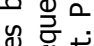

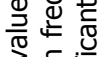

还 둔

흘

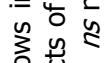

究进客

웅용ㅇํㅇㅇ

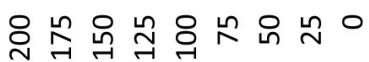

范

恶*

बंष्ठ

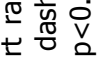

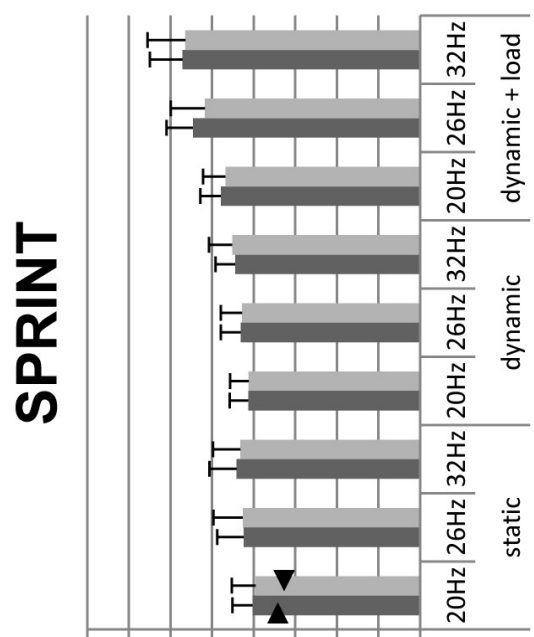

焉喜

है

齐

त诺

묵

흘

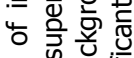

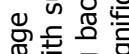

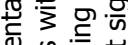

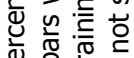

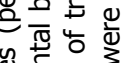

里家

政离.

尊方

응용ㅇㅇㅇㅇㅇㅇ

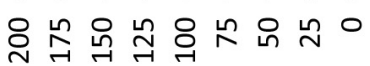

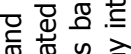

我 范

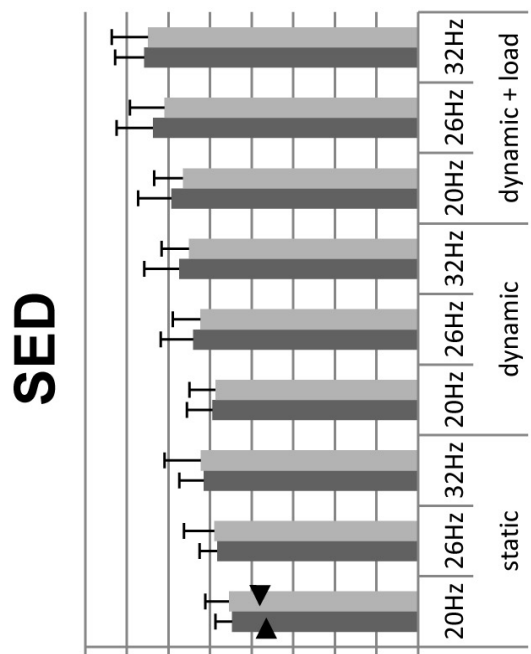

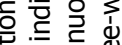

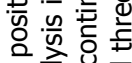

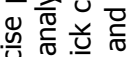

这

语式示

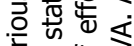

穷

o

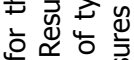

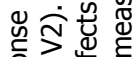

응 눙

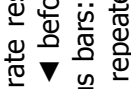

七彭.

용ㅇㅇㅇํㅇㅇㅛ

xeury $\%$

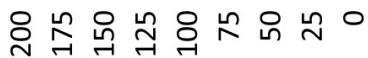

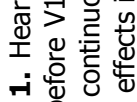

[๘-U!u] $\mathbf{y H}$

这全鱼 


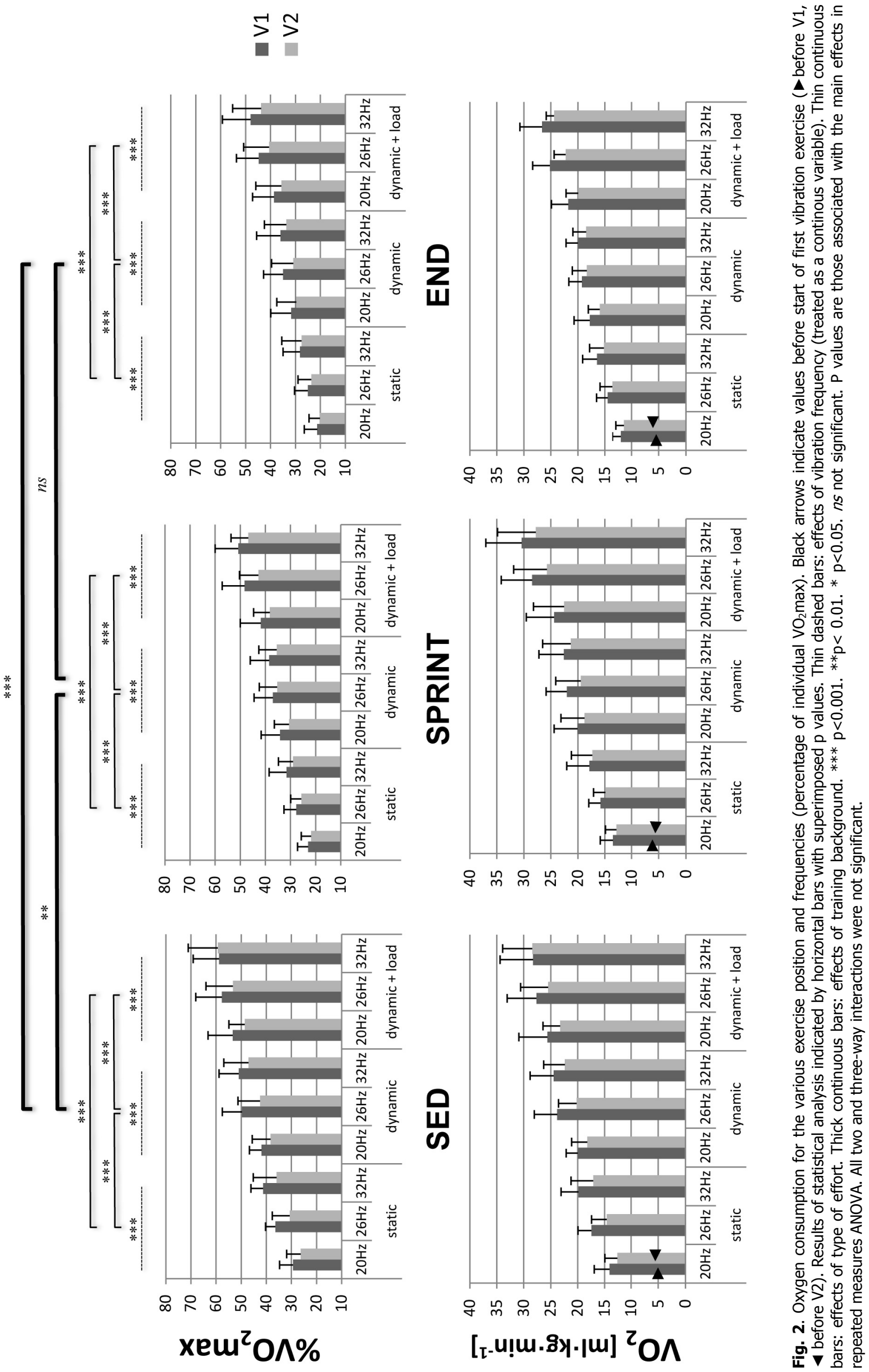


Effect of exercise type and vibration frequency

Oxygen uptake increased with vibration frequency $(\mathrm{p}<0.01)$, and also from isometric to dynamic to dynamic loaded squats $(\mathrm{p}<0.001)$.

\section{Effect of familiarization}

All subjects presented lower $\mathrm{O}_{2}$ uptake values in the second session (V2), and showed an ability to carry out the drills more efficiently $(\mathrm{p}<0.001)$.

\section{Effect of athletic background}

SED had the highest relative $\mathrm{VO}_{2}$ response ( $p<0.01$ compared to SPRINT, $p<0.001$ compared to END). END and SPRINT had a similar response. The addition of age, weight, and BMI as covariates in the repeated measures ANOVA had negligible impact on the results of statistical analysis.

\section{Perceived effort}

\section{Effect of exercise type and vibration frequency}

In all three groups Borg score increased with vibration frequency $(\mathrm{p}<0.001)$, but no differences were present between isometric and dynamic squats, while loaded squats elicited higher scores than the other two exercises $(\mathrm{p}<0.001)$.

\section{Effect of familiarization}

There was a significant difference between both vibration sessions in all subjects, with an average decrease in Borg value of 0.7 (SED), 1.5 (SPRINT) and 1.0 (END) $(\mathrm{p}<0.001)$ from V1 to V2.

\section{Effect of athletic background}

No differences were present between groups. The addition of age, weight, and BMI as covariates in the repeated measures ANOVA had negligible impact on the results of statistical analysis.

\section{Discussion}

We have investigated the impact on heart rate and oxygen uptake of three different side-alternating vibration training exercises in sedentary or trained subjects, at three different vibration frequencies. The main new result is that the elicited exercise intensity depends on all of these variables. Namely, exercise intensity, measured as percentage of maximal heart rate (HRmax) or of maximal oxygen uptake $\left(\mathrm{VO}_{2} \mathrm{max}\right)$, increases with frequency, and as subjects progress from static squats, to dynamic squats and finally to loaded dynamic squats. These facts should be taken into consideration when the effect of WBV exercises on health and fitness is discussed.

We observed that typical squatting exercises for three continuous minutes can elicit sufficient heart rate and oxygen uptake responses in order to have a potential health and fitness enhancing effect in sedentary subjects, more so than in trained athletes. This is to our knowledge the first time a comparison of the metabolic response in differently trained subjects is reported for WBV exercises.

\section{Athletes}

In athletes, it is obviously not the goal to use WBV for any cardiovascular training purposes, and benefits for improvements in strength and power have been reported (Ronnestad 2004, Fagnani et al. 2006, Mahieu et al. 2006), but in general the WBV program is not more effective than a regular resistance training program in order to improve muscle strength or power. One study measured energy expenditure in recreationally resistance trained subjects with or without vibration during a training session involving 5 sets of 10RM halfsquats (to 90 degrees knee flexion), and reported an $18 \%$ higher energy expenditure with vibration, although heart rate was not significantly higher (Da Silva et al. 2007). Our athletes were either strength trained (mostly sprinters - SPRINT) or endurance trained (runners and triathletes END). All relative $\mathrm{VO}_{2}$ responses $\left(\% \mathrm{VO}_{2} \max \right)$ were lower in athletes when compared to sedentary subjects, which is expected, since the athletes have by definition a higher baseline aerobic fitness level and each exercise should require a similar amount of energy to be produced by all subjects. But we also observed a 10-15\% lower absolute $\mathrm{O}_{2}$ uptake for each exercise type and frequency in SPRINT compared to SED and END (data not shown). This means that the task efficiency or economy of exercise is better in SPRINT, potentially because of better neuro-muscular ability to generate muscle contractions directed at accomplishing the task at hand (squatting). This type of exercise is one that is as a general rule part of their usual training, and therefore more specific to their abilities. On the other hand END showed no differences compared to SED in absolute $\mathrm{VO}_{2}$ for each task, reflecting their similar task efficiency and lack of specific training for squatting. When relative heart rate is considered, we observed that the END athletes had lower percentages of HRmax compared to SED and SPRINT. 


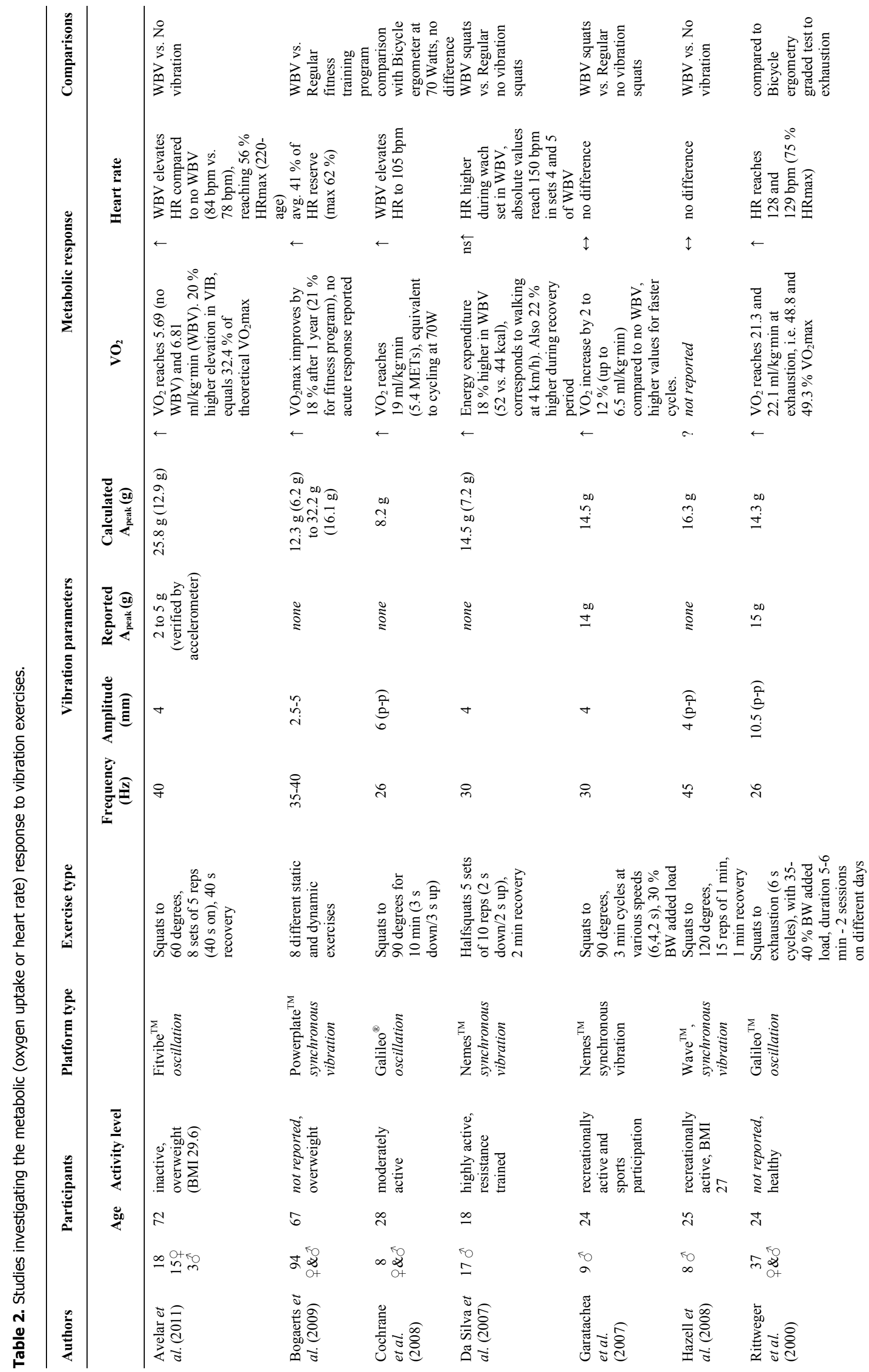




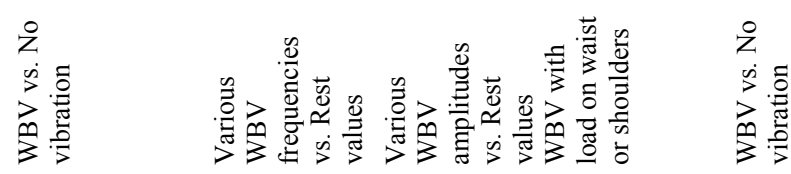

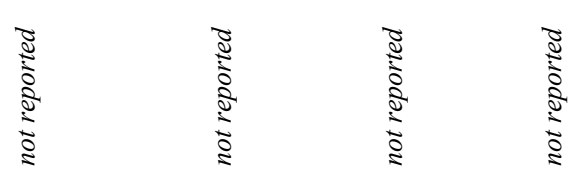

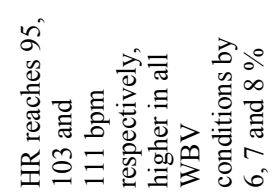

言笻

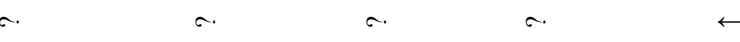

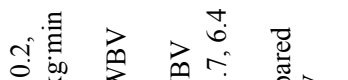

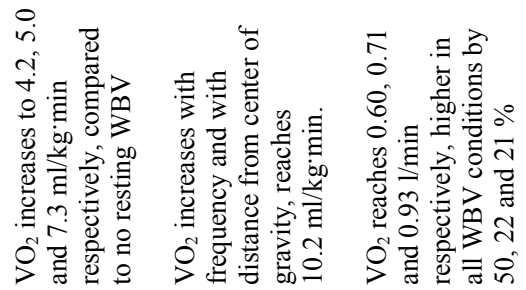

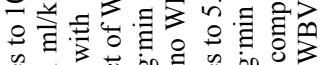

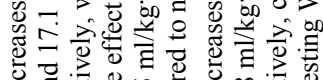

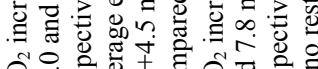

今.

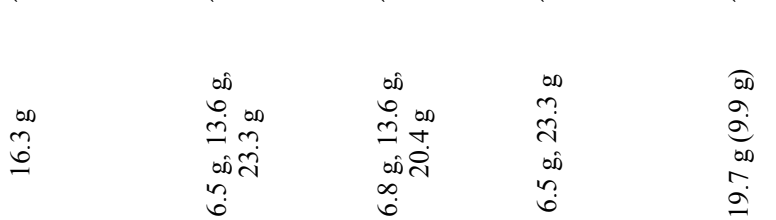

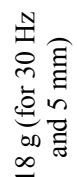<smiles>[CH]1[CH]C[CH]1</smiles>

$\cong$

$\cong$

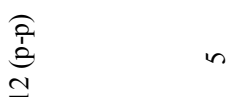

$\underset{n}{n} \underset{n}{n}+$

¿

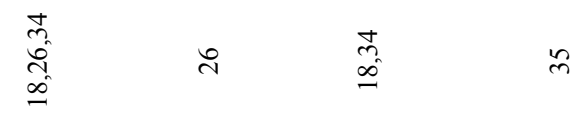

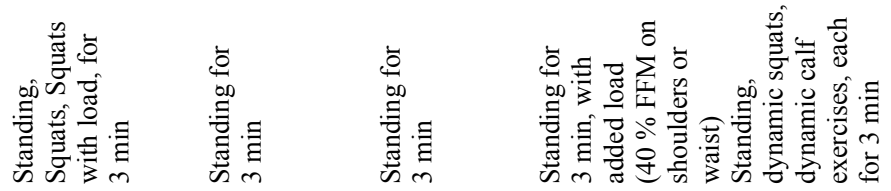

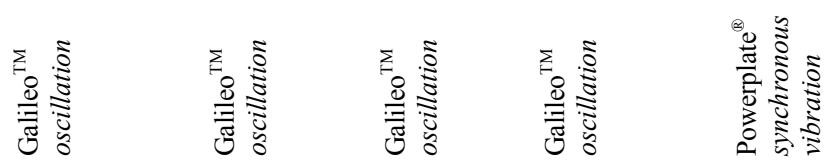

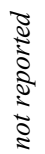

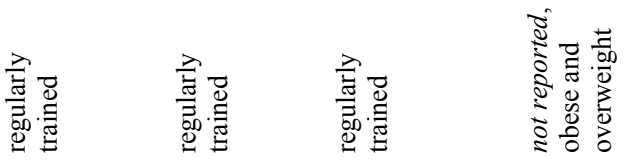

$\stackrel{\sim}{\sim} \quad \stackrel{\sim}{\sim} \quad \infty$

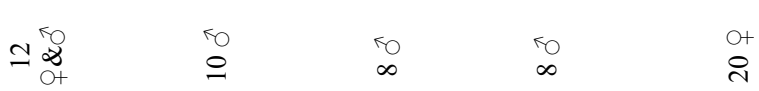

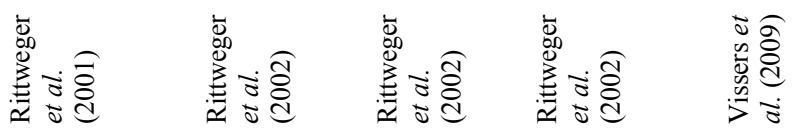

ष्षे

\begin{tabular}{|c|c|c|c|}
\hline 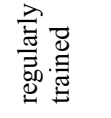 & 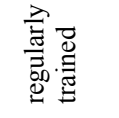 & 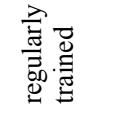 & 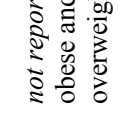 \\
\hline$\stackrel{\infty}{\sim}$ & $\stackrel{\infty}{\sim}$ & $\stackrel{\infty}{\sim}$ & $\underset{m}{\infty}$ \\
\hline \begin{tabular}{l}
$i_{0}$ \\
\hdashline
\end{tabular} & $\begin{array}{l}\gamma_{0} \\
\infty\end{array}$ & $\begin{array}{l}r_{0} \\
\infty\end{array}$ & $\begin{array}{l}\text { O+ } \\
\stackrel{\sim}{+}\end{array}$ \\
\hline 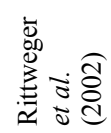 & 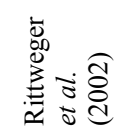 & 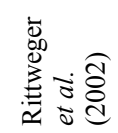 & 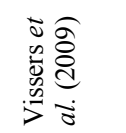 \\
\hline
\end{tabular}


The increased metabolic demand of the exercises elicited different chronotropic adaptations in END, with a lower heart rate response, although the absolute $\mathrm{VO}_{2}$ was similar to SED, which could be explained by their probable increased heart compliance and contractility, resulting in a more pronounced increase in stroke volume, although this was not measured in our protocol.

\section{Sedentary subjects}

As the untrained subjects have a lower $\mathrm{VO}_{2}$ max, a higher percentage of $\mathrm{VO}_{2} \mathrm{max}$ is necessary for the completion of the exercises, but we also observed that the energetic cost (when looking at absolute oxygen uptake) was higher in SED overall. As discussed above, one explanation lies in the fact that SED are unaccustomed to these various types of muscle contractions, do not have as good a balance as athletes, and are thus more prone to accessory muscle use and compensations which raise the metabolic demand. In a similar exercise protocol, Rittweger et al. (2000) have observed a lower $\mathrm{VO}_{2}$ and heart rate response compared to our results, in young healthy male and female subjects: during continuous dynamic squatting to exhaustion with additional load ( $40 \%$ of body weight for males and $35 \%$ for females), they were only able to elevate oxygen uptake to $49 \%$ of $\mathrm{VO}_{2}$ max, while their peak heart rate was $128 \mathrm{bpm}$ or $75 \%$ of HRmax determined in a maximal bicycle ergometer test. Their protocol differed from ours in that it was an exercise to exhaustion that lasted 5 to $6 \mathrm{~min}$, while our subjects did the exercise for three times three minutes with one minute recovery between bouts. If we look at the oxygen uptake at the end of the second bout, i.e. six minutes of exercise, our sedentary subjects who were doing dynamic squatting with additional load at $26 \mathrm{~Hz}$ (with a similar peak-to-peak displacement as the subjects in Rittweger's study) reached $57.7 \%$ of $\mathrm{VO}_{2} \max$, which is higher than the $49 \%$ they observed. Our last three minute bout elevated oxygen uptake to $58.8 \%$. As for heart rate, our subjects reached $80.1 \%$ of HRmax after six minutes and $82.7 \%$ after nine minutes. Recently Avelar et al. (2011) showed in elderly inactive subjects that squatting with vibration increased $\mathrm{O}_{2}$ uptake by $20 \%$ compared to normal squatting, although the absolute values reached only $6.8 \mathrm{ml} \cdot \mathrm{kg}^{-1} \cdot \mathrm{min}^{-1}$ (2 METs). Their vibration settings generated accelerometer measurements of 2 to $5 \mathrm{~g}$. These low acceleration values could explain the smaller metabolic effect seen in their subjects compared to our sedentary subjects. In further experiments, Rittweger's group confirmed an elevated oxygen uptake with added vibrations (Rittweger et al.
2001, 2002), albeit the peak $\mathrm{VO}_{2}$ attained with vibrations in their study was lower than in ours. Squatting for $3 \mathrm{~min}$ with vibration elevated $\mathrm{O}_{2}$ uptake to $14.0 \mathrm{ml} \cdot \mathrm{kg}^{-1} \cdot \mathrm{min}^{-1}$, while our subjects doing the same vibration exercise reached $22.8 \mathrm{ml} \cdot \mathrm{kg}^{-1} \cdot \mathrm{min}^{-1}(\mathrm{~V} 1)$, and $20.1 \mathrm{ml} \cdot \mathrm{kg}^{-1} \cdot \mathrm{min}^{-1}$ (V2). We believe that our protocol with intermittent short recovery allowed our subjects to go to higher intensities of exercise, which is typical of interval training techniques, but these differences are important and still difficult to explain. Rittweger et al. (2002) conclude that the amount of $\mathrm{O}_{2}$ uptake they observed elicits an energy expenditure comparable to moderate walking. Others have also observed elevated $\mathrm{O}_{2}$ uptake with various WBV exercises and settings (Da Silva et al. 2007, Garatachea et al. 2007, Cochrane et al. 2008, Vissers et al. 2009). Table 2 summarizes the studies that have measured oxygen uptake or heart rate response to vibration exercise.

From these various studies, it appears that there is an important variability in the amount of oxygen uptake elicited by various vibration exercises, and especially by different vibration platforms and settings (frequency and amplitude). Although some of the studies use similar technology with almost equivalent peak accelerations, the $\mathrm{VO}_{2}$ response varies. To address this discrepancy, a few possible explanations can be offered. First, the vibration settings reported in the various studies lack standardization, most notably for amplitude, which needs to be reported as peak-to-peak displacement to avoid any confusion. Second, the numbers reported for frequency and amplitude are the ones given by the platform manufacturers, and only very few of the studies discussed previously have reported actual parameters, with measurements done by accelerometers. The accuracy of the data from manufacturers would need to be experimentally challenged, as it seems that certain devices are more reliable and accurate than others. One study looked at actual measurements of mechanical properties of different platforms, finding that those ones most commonly used in research (Galileo 2000®) and Powerplate $(\mathbb{R})$ were more reliable than others (Pel et al. 2009), which is also confirmed by the accelerometer measurements done by Avelar et al. (2011) on their platform. Admittedly, our device was not tested for accuracy and this may play a role in our observations. Third, the studies generally do not report the type of shoes worn by the subjects and their potential damping effect. Our subjects wore only regular unpadded socks, which could have minimized vibration damping and therefore elicited more muscle response compared to subjects who 
would be wearing athletic shoes. This has not been measured or compared, though, and could be addressed in the future, as it is accepted that the transmission of vibration diminishes importantly as it travels its way up the musculoskeletal chain from the foot up (Pel et al. 2009).

Physical fitness and health have been extensively studied in the last few decades, and most of the studies put emphasis on cardiovascular fitness, i.e. aerobic fitness, by measurement or estimation of $\mathrm{VO}_{2} \mathrm{max}$. Lately however, muscular strength has been shown to help reduce overall and cancer mortality, independently of aerobic fitness (Ruiz et al. 2008), and the accumulated evidence has led to the latest exercise and physical activity guidelines from the American College of Sports Medicine (ACSM), which insist on the benefits of an endurance-type and resistance-type activity (Haskell et al. 2007). WBV exercises have already shown benefits for strength, especially in population subgroups that have a lower starting strength (elderly, middle-aged and inactive women). A couple of studies have shown positive effects on $\mathrm{VO}_{2} \max$ through a WBV training program of 2 months (Behboudi et al. 2011) and 12 months (Bogaerts et al. 2009), while others claim that the increased metabolic stimulation by added vibration cannot be sufficient to that effect (Rittweger 2009, Cochrane 2011). In our trial, typical exercises such as the dynamic squat raised oxygen uptake close to $50 \%$ of $\mathrm{VO}_{2} \mathrm{max}$, which corresponded to $65-70 \%$ of HRmax, and also fits the definition of vigorous physical activity (>6 METs). These exercises can meet the ACSM guidelines on exercise training for health (Haskell et al. 2007) and dynamic WBV exercise at $\geq 26 \mathrm{~Hz}$ or isometric squats at $32 \mathrm{~Hz}$, carried out three times per week for at least $20 \mathrm{~min}$, could fulfill the requirements for physical activity for health (450-750 MET·min $\left.\cdot \mathrm{wk}^{-1}\right)$ (Fig. 3).

\section{MET.min. $\mathbf{w k}^{-1}$}

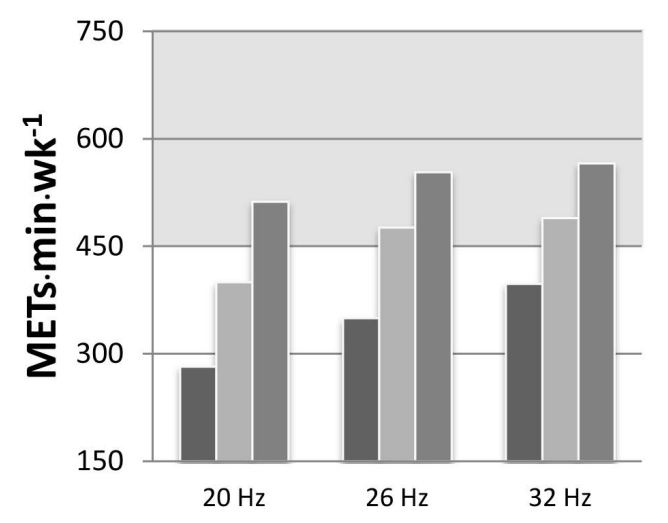

MET

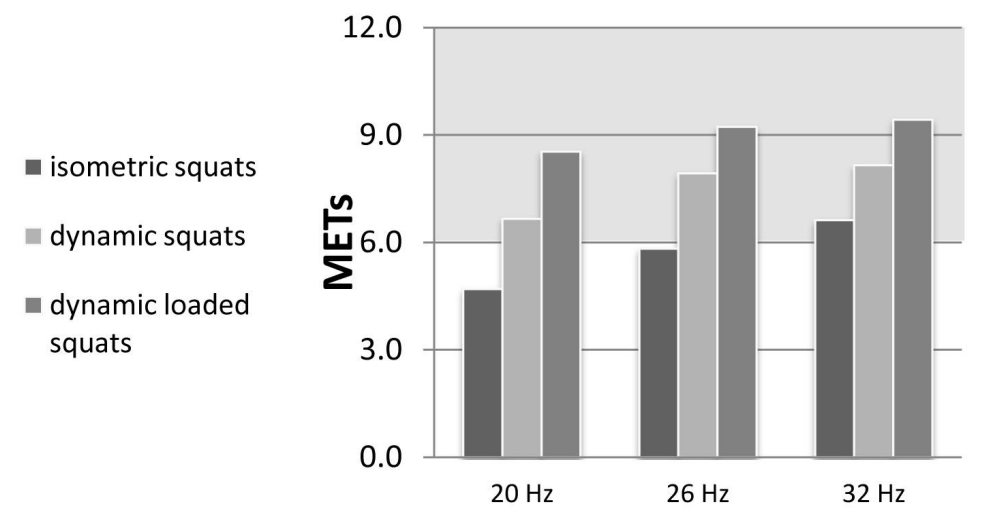

Fig. 3. Exercise intensities in METs (right) and corresponding total weekly energy expenditure in MET'min' $\mathrm{wk}^{-1}$ (left), if three weekly WBV sessions of at least twenty minutes were carried out, in sedentary subjects (SED). The shaded upper zone corresponds to exercise intensities (right) above the definition of vigorous physical activity (>6 METs), and weekly totals (left) sufficient to meet physical activity guidelines $\left(450-750 \mathrm{MET} \cdot \mathrm{min}^{\cdot} \mathrm{wk}^{-1}\right)$.

\section{Limitations}

The main limitation in our design is the lack of comparison with the absence of vibration. However our main purpose was to investigate the impact of exercise type and the dose-responses relationships with vibration frequency. The very existence of the latter, clearly shown by our results, implies that vibrations per se had an effect, as reported by other studies. In addition, the different exercise conditions were not randomized, but carried out one after the other in a sequence that aimed to increase the intensity with time. This was confirmed by the data, but a fatiguing effect of previous exercise might have modified the response to the subsequent one. Another issue that can raise a few questions is the familiarization with the exercise. We saw that the second session (V2) elicited lower responses in all measurements, and it is not known what the response would be after a longer time of adaptation to this type of training. We think a habituation effect will certainly be present to some extent. We also acknowledge the facts that our sample size was small and that the vibration platform settings (frequency and amplitude) have not been measured objectively in our protocol, as we relied on the parameters given by the manufacturer, which should not be the case if possible in future research. 


\section{Conclusion}

Our study shows that the metabolic and heart rate response to WBV depend on fitness level and type, and especially that young sedentary or untrained individuals could potentially benefit from WBV training for overall fitness, alongside gains in strength already shown in other studies (Rehn et al. 2007, Marin and Rhea 2010). With the growing interest in WBV, we believe our observations bring an addition to the potential benefits for health of this new training modality.

\section{Acknowledgements}

This study was funded by departmental funds only. The authors thank Chantal Daucourt for her help with technical issues during data collection. Boris Gojanovic (BG), Francois Feihl (FF) and Bernard Waeber (BW) discussed the original idea and contributed equally to the study design. BG and Gerald Gremion (GG) contributed to subjects inclusion, data collection and processing, while FF and BW helped also with data analysis. BG wrote the initial manuscript and all authors contributed to final editing.

\section{Conflict of Interest}

There is no conflict of interest.

\section{References}

AVELAR NC, SIMAO AP, TOSSIGE-GOMES R, NEVES CD, MEZENCIO B, SZMUCHROWSKI L, COIMBRA CC, LACERDA AC: Oxygen consumption and heart rate during repeated squatting exercises with or without whole-body vibration in the elderly. $J$ Strength Cond Res 25: 3495-3500, 2011.

BAUTMANS I, VAN HEES E, LEMPER JC, METS T: The feasibility of Whole Body Vibration in institutionalised elderly persons and its influence on muscle performance, balance and mobility: a randomised controlled trial [ISRCTN62535013]. BMC Geriatr 5: 17, 2005.

BEHBOUDI L, AZARBAYJANI MA, AZARBAYJANI H, SALAVATI M: Effects of aerobic exercise and whole body vibration on glycaemia control in type 2 diabetic males. Asian J Sports Med 2: 83-90, 2011.

BOGAERTS AC, DELECLUSE C, CLAESSENS AL, TROOSTERS T, BOONEN S, VERSCHUEREN SM: Effects of whole body vibration training on cardiorespiratory fitness and muscle strength in older individuals (a 1-year randomised controlled trial). Age Ageing 38: 448-454, 2009.

BRUYERE O, WUIDART MA, DI PALMA E, GOURLAY M, ETHGEN O, RICHY F, REGINSTER JY: Controlled whole body vibration to decrease fall risk and improve health-related quality of life of nursing home residents. Arch Phys Med Rehabil 86: 303-307, 2005.

CARDINALE M, SOIZA RL, LEIPER JB, GIBSON A, PRIMROSE WR: Hormonal responses to a single session of wholebody vibration exercise in older individuals. Br J Sports Med 44: 284-288, 2010.

COCHRANE DJ: Vibration exercise: the potential benefits. Int J Sports Med 32: 75-99, 2011.

COCHRANE DJ, STANNARD SR, SARGEANT AJ, RITTWEGER J: The rate of muscle temperature increase during acute whole-body vibration exercise. Eur J Appl Physiol 103: 441-448, 2008.

DA SILVA ME, FERNANDEZ JM, CASTILLO E, NUNEZ VM, VAAMONDE DM, POBLADOR MS, LANCHO JL: Influence of vibration training on energy expenditure in active men. J Strength Cond Res 21: 470-475, 2007.

FAGNANI F, GIOMBINI A, DI CESARE A, PIGOZZI F, DI SALVO V: The effects of a whole-body vibration program on muscle performance and flexibility in female athletes. Am J Phys Med Rehabil 85: 956-962, 2006.

GARATACHEA N, JIMENEZ A, BRESCIANI G, MARINO NA, GONZALEZ-GALlEGO J, DE PAZ JA: The effects of movement velocity during squatting on energy expenditure and substrate utilization in whole-body vibration. J Strength Cond Res 21: 594-598, 2007.

GAUTHIER AP, LARIVIERE M, YOUNG N: Psychometric properties of the IPAQ: a validation study in a sample of northern Franco-Ontarians. J Phys Act Health 6 (Suppl 1): S54-S60, 2009.

GUSI N, RAIMUNDO A, LEAL A: Low-frequency vibratory exercise reduces the risk of bone fracture more than walking: a randomized controlled trial. BMC Musculoskelet Disord 7: 92, 2006. 
HASKELL WL, LEE IM, PATE RR, POWELL KE, BLAIR SN, FRANKLIN BA, MACERA CA, HEATH GW, THOMPSON PD, BAUMAN A: Physical activity and public health: updated recommendation for adults from the American College of Sports Medicine and the American Heart Association. Med Sci Sports Exerc 39: 1423-1434, 2007.

HAZELL TJ, THOMAS GW, DEGUIRE JR, LEMON PW: Vertical whole-body vibration does not increase cardiovascular stress to static semi-squat exercise. Eur J Appl Physiol 104: 903-908, 2008.

LORENZEN C, MASCHETTE W, KOH M, WILSON C: Inconsistent use of terminology in whole body vibration exercise research. J Sci Med Sport 12: 676-678, 2009.

MAHIEU NN, WITVROUW E, VAN DE VOORDE D, MICHILSENS D, ARBYN V, VAN DEN BROECKE W: Improving strength and postural control in young skiers: whole-body vibration versus equivalent resistance training. J Athl Train 41: 286-293, 2006.

MARIN PJ, RHEA MR: Effects of vibration training on muscle strength: a meta-analysis. J Strength Cond Res $\mathbf{2 4}$ 548-556, 2010.

MYERS J, PRAKASH M, FROELICHER V, DO D, PARTINGTON S, ATWOOD JE: Exercise capacity and mortality among men referred for exercise testing. $N$ Engl J Med 346: 793-801, 2002.

NAZAROV V, SPIVAK G: Development of athlete's strength abilities by means of biomechanical stimulation method (in Russian). Theory and Practice of Physical Culture 12: 445-450, 1985.

PEL JJ, BAGHERI J, VAN DAM LM, VAN DEN BERG-EMONS HJ, HOREMANS HL, STAM HJ, VAN DER STEEN J: Platform accelerations of three different whole-body vibration devices and the transmission of vertical vibrations to the lower limbs. Med Eng Phys 31: 937-944, 2009.

REHN B, LIDSTROM J, SKOGLUND J, LINDSTROM B: Effects on leg muscular performance from whole-body vibration exercise: a systematic review. Scand J Med Sci Sports 17: 2-11, 2007.

RITTWEGER J: Vibration as an exercise modality: how it may work, and what its potential might be. Eur J Appl Physiol 108: 877-904, 2009.

RITTWEGER J, BELLER G, FELSENBERG D: Acute physiological effects of exhaustive whole-body vibration exercise in man. Clin Physiol 20: 134-142, 2000.

RITTWEGER J, SCHIESSL H, FELSENBERG D: Oxygen uptake during whole-body vibration exercise: comparison with squatting as a slow voluntary movement. Eur J Appl Physiol 86: 169-173, 2001.

RITTWEGER J, EHRIG J, JUST K, MUTSCHELKNAUSS M, KIRSCH KA, FELSENBERG D: Oxygen uptake in whole-body vibration exercise: influence of vibration frequency, amplitude, and external load. Int J Sports Med 23: 428-432, 2002.

ROBERGS RA, DWYER D, ASTORINO T: Recommendations for improved data processing from expired gas analysis indirect calorimetry. Sports Med 40: 95-111, 2010.

RONNESTAD BR: Comparing the performance-enhancing effects of squats on a vibration platform with conventional squats in recreationally resistance-trained men. J Strength Cond Res 18: 839-845, 2004.

RUIZ JR, SUI X, LOBELO F, MORROW JR JR, JACKSON AW, SJOSTROM M, BLAIR SN: Association between muscular strength and mortality in men: prospective cohort study. BMJ 337: a439, 2008.

SESSO HD, PAFFENBARGER RS JR, LEE IM: Physical activity and coronary heart disease in men: The Harvard Alumni Health Study. Circulation 102: 975-980, 2000.

SLATKOVSKA L, ALIBHAI SM, BEYENE J, CHEUNG AM: Effect of whole-body vibration on BMD: a systematic review and meta-analysis. Osteoporos Int 21: 1969-1980, 2010.

TSCHOPP M: Performance Diagnostics. In: Book Performance Diagnostics. Swiss Olympic Medical Centers (ed.) Davos, Loèche-les-Bains, Macolin, Muttenz, Zurich, 2003, p. 63.

VERSCHUEREN SM, ROELANTS M, DELECLUSE C, SWINNEN S, VANDERSCHUEREN D, BOONEN S: Effect of 6-month whole body vibration training on hip density, muscle strength, and postural control in postmenopausal women: a randomized controlled pilot study. J Bone Miner Res 19: 352-359, 2004.

VISSERS D, BAEYENS JP, TRUIJEN S, IDES K, VERCRUYSSE CC, VAN GAAL L: The effect of whole body vibration short-term exercises on respiratory gas exchange in overweight and obese women. Phys Sportsmed 37: 88-94, 2009. 
VISSERS D, VERRIJKEN A, MERTENS I, VAN GILS C, VAN DE SOMPEL A, TRUIJEN S, VAN GAAL L: Effect of long-term whole body vibration training on visceral adipose tissue: a preliminary report. Obes Facts 3: 93-100, 2010.

WARBURTON DE, NICOL CW, BREDIN SS: Health benefits of physical activity: the evidence. CMAJ 174: 801-809, 2006. 